\title{
A questão do referente em alguns fotógrafos contemporâneos
}

Kati Eliana Caetano Universidade Tuiuti do Paraná/UTP

Osvaldo Santos Lima Universidade Tuiuti do Paraná/UTP 


\section{Resumo}

Embora seja fato suficientemente conhecido o caráter ilusório da fotografia como reprodução do real, e se tenham explorado as suas potencialidades para construir e desconstruir o que se concebeu durante muito tempo como imagens rigorosas do mundo, tanto do ponto de vista artístico quanto teórico, o tema volta com força na contemporaneidade suscitando novas reflexões. Neste ensaio foram selecionados alguns fotógrafos atuais, cuja obra está pautada nessa busca obsessiva entre a fotografia e a realidade, por meio de estratégias diversas que vão de um uso secundário do processo de iconização das imagens até a definição do ato fotográfico como o resultado de um encontro intersubjetivo em permanente construção.

\section{Palavras-chave}

comunicação visual, fotografia, representação, plano de expressão, referente

\section{Abstract}

Although the illusory characteristic of the photography as reproduction of the real can be a fact sufficiently known, and its potentialities, in order to construct and deconstruct what is conceived as strict images of the world, have been widely explored either by the artistic and theoretical point of view, the issue returns in the contemporaneity, raising new reflections. In this essay, some present day photographers are selected, whose works are directed to the obsessive search between the photography and reality through many strategies: from a secondary use of the iconization process of the images up to the definition of the photographic act as a result of an intersubjective encounter in permanent construction.

\section{Key words}

visual communication, photography, representation, plan of expression, referent 
$\mathrm{H}$ á muito tempo já se desvelou o caráter simbólico da fotografia, deixando de considerá-la como uma reprodução minuciosa da realidade. O "isso foi" da fotografia, preconizado por Barthes (1984), anunciou não só a morte da natureza realista da fotografia, mas também a sua marca de signo.

No entanto, reiteradas vezes artistas da fotografia têm pautado seu trabalho pela busca da realidade, mesmo que distinta do tradicional efeito documental da fotografía em relação ao objeto representado.

Esse é o caso de alguns dos mais representativos fotógrafos internacionais da contemporaneidade, cujas obras serão examinadas neste texto. Mais precisamente, o foco da análise consiste em algumas imagens, em certos casos associadas aos discursos dos próprios artistas sobre o fazer fotográfico, nos quais se explicita a intenção artística de retratar a realidade, ou de fazer manifestar a sua essência.

A questão da referencialidade como efeitos de sentido de realidade ou de verdade, portanto como construções simbólicas do real, já foi suficientemente discutida e encontrou na fotografia vasto campo de análise. $\mathrm{O}$ que interessa atualmente é compreender as diferentes formas de sua manifestação. Desđe o século XIX, no bojo do próprio movimento do "grande" realismo, evidenciaram-se tendências que relativizavam essa noção, construindo efeitos realistas por meio da fragmentação, da distorção, da multiplicação de aspectos do objeto, ou pela fíccionalização do leitor/fruidor, em vez de referencialização do objeto relatado, que visava a dar a impressão de realidade pela tentativa de fidelidade figurativa.

Em consequencia, os gêneros se contaminaram e não se sabe mais ao certo distinguir entre uma crônica literária e jornalística, entre uma notícia uma publicidade, entre uma reportagem e um 
conto policial, entre uma pintura e uma fotografia, seja pela característica de seus recursos expressivos, seja pelo fato de que remetem a temáticas que transitam entre o que se convencionou chamar de ficção e realidade. Nos dias atuais, esse processo se consolidou, gerando produtos artísticos exemplares que diluem as fronteiras entre o impresso e o multimídia, entre a arte e a ciência.

Mas o que faz um artista contemporâneo perguntar-se ainda, nesse contexto múltiplo, sobre o que é realidade? Ou talvez seja mais apropriado questionar de que maneira a busca da verdade do mundo parece se configurar nas obras daqueles que propositadamente imergem nessa investigação estética?

É assim que as fotos da francesa Sophie Calle, do alemão Thomas Ruff, do canadense Jeff Wall, do americano Lewis Baltz e do brasileiro Miguel Rio Branco serão abordadas, pela análise de alguns dos procedimentos presentes em seus discursos.

\section{A construção do objeto fotográfico}

O empenho em retratar a realidade foi substituído nos nossos dias por uma necessidade de configurar o próprio objeto fotográfico, de construi-lo conscientemente para apreendê-lo em seguida no suporte da fotografia. Não se trata mais, portanto, da fidelidade figurativa com o real, mas uma atitude em direção à fabricação consciente do objeto e ao maior compartilhamento do outro, daquele que olha a fotografia, na reconstituição desse percurso. Como Greimas já havia apontado em relação ao discurso visual, o objeto semiótico não deve ser considerado como um dado, mas o resultado de uma leitura que o constrói. (1984, p. 29)

A contrapartida de tal empreendimento é o afastamento cada vez mais acentuado (ou o efeito de sentido de um afastamento) da perspectiva do fotógrafo no objeto representado. Buscamse coisas, situações, impressões que falem por si mesmas, tentando captar a essência dos sentimentos nos vínculos intersubjetivos e nos vínculos dos homens com os objetos, mais do que a figuração do mundo. Se, conforme nos ensina a semiótica da interação (Fontanille, 1999; Landowski, 2001), a semiose não se inscreve nem 
no objeto, nem no sujeito, mas na relação desse encontro, é evidente que tal busca resulta numa empreitada meio obsessiva (como se verá especificamente com os trabalhos de Sophie Calle), meio delirante, e ao tempo, ou talvez por isso, frustrada. O objeto revela-se escorregadio, mesmo em sua aparência objetivante, e o sujeito premido pelas coerções da passagem do percebido em objeto e, por conseguinte, pelo peso do seu crivo de leitura na simulação do objeto-imagem.

A câmara obscura parece ter consigo parte da explicação para a passagem do figurativo à fabricação consciente do objeto fotográfico. Seu primeiro uso prático foi auxiliar desenhistas na tarefa de copiar cenas e objetos devido a sua impressionante qualidade perspéctica. A mão do artista foi a única maneira de registro da imagem até a descoberta da fotografia, que consistiu na união do princípio físico da câmera obscura com a capacidade de registro químico, da energia luminosa, pelos sais de prata. Com isso o aparelho revelou sua vocação referencial que serviu de inspiração para a poética denominação de "espelho com memória" para a nova descoberta.

O registro mecânico era uma potencialidade do aparelho que até o início do século XIX não havia sido explorada. Talvez, sem essa capacidade, a câmera obscura figuraria historicamente próxima ao diadorama ou a um teatro de sombras. Uma multidão, fascinada pelo aparelho, se entregou ao ofício de fotógrafo e ao fazê-lo incorporou, como natureza única do processo fotográfico, o seu fascínio inicial: a capacidade da fotografia de reprodução de "detalhes verídicos" e com efeitos surpreendentes de fazer-parecido, que se distingue de tentativas similares da pintura renascentista pelo fato de que faz crer na existência real do objeto fotografado.

A imagem projetada pelo orifício da câmera obscura é invertida e circular. O processo de "reversão" da imagem resulta de uma relação fortemente referencial com o mundo retratado. Mas ao determinar um quadro para a captura, subvertendo a natureza circular da imagem, o homem criou um novo estatuto baseado nessa intervenção primária. A moldura se tornou o primeiro filtro de acesso ao universo exterior e janela metafórica ao ligar o mundo 
interno ao externo, o interoceptivo ao exteroceptivo, o operator ao spectator numa dinâmica de relações latentes do aparelho e agora realizadas pela vontade e obra humana. $O$ fascínio inicial que se detinha no orifício de entrada dos raios luminosos, janela responsável pela contigüidade física do referente, foi migrando para uma outra janela na fotografia contemporânea. Do orifício, que dá conta da representação figurativa do referente, passa-se à moldura, que representa o poder daquele que opera o aparelho.

Assim traduzida como janela metafórica, a moldura, na qualidade de "fechamento" (Greimas, op. cit., p. 32) imaginário do objeto, se incorporou à feição da fotografia contemporânea, que passa a ser encarada como naturalmente recortada, ou como um recorte natural de uma "quadratura" do real. Pelo recurso da metáfora o fotógrafo pôde percorrer o árduo percurso, entre uma janela e outra, que o separava daquele que olha a fotografia. Com a inserção da imagem captada na moldura, intervenção primária do operator barthesiano condicionada à própria ontologia do suporte, opera-se a transformação do percebido em objeto, primeiro crivo de leitura do mundo na fixação de imagens. Como afirma Greimas,

Ato deliberado do produtor que, colocando-se ele próprio no espaço da enunciação "fora-do-quadro", instaura, por meio de uma espécie de debreagem, um espaço enunciado do qual sera o único comandante, capaz de criar um "universo utópico" separado desse ato: garantindo, desse modo, ao objeto circunscrito o estatuto de "um todo de significação", esse fechamento é também o ponto de partida das operações de deciframento da superficie enquadrada. (p. 32)

Da conquista de um dispositivo de fixação de imagens, que permite ao outro situar-se no mesmo ponto de percepção do mundo em que se instala o operador da máquina fotográfica, o passo seguinte foi o de construir superfícies que justamente deslocassem os pontos usuais de focalização daquilo que nos rodeia. Desde angulações e tomadas absolutamente insólitas, que davam vida e significação ao 
que antes era mero detalhe, até experiências mais extravagantes, de que resultaram anamorfoses diversas, inclusive as anamorfoses cronotópicas de que fala Arlindo Machado (1993), ou a manifestação da dimensão do tempo no espaço, a questão do encontro entre o homem e a realidade sempre esteve no seio das preocupações do artista da fotografia.

Esse interesse se traduz recentemente, entre vários artistas consagrados da contemporaneidade, como uma tentativa de buscar na "essência" dos objetos, naquilo que a sua presença impõe ao ser captado pelo olhar do outro a manifestação da realidade ou da verdade. Dessa experiência, surgem resultados distintos e constatações sobre a relação entre o sujeito e o objeto no processo do fazer fotográfico, assim como os vínculos entre a fotografia e o ser/estar no mundo. Algumas dessas obras serão analisadas aqui. ${ }^{1}$

\section{A "obscenidade" de Lewis Baltz}

$\mathrm{Na}$ busca incessante de representar as formas mais banais com a maior objetividade possível, sem marcar o seu ponto de vista, o americano Lewis Baltz procura nos objetos marginalizados, no sentido de não-valorizáveis pelas axiologias coletivas, o foco de sua atenção para conjugar-se com a realidade e a verdade das coisas. Chama esses objetos de coisas "obscenas", no sentido de fora da cena, associando-os a terrenos vazios e lixos espalhados pelo chão, sobre os quais efetua uma varredura da câmera na tentativa de extrair deles não só sua essência semântica, mas a própria particularidade do objeto expressa em alguns de seus fragmentos. Opera-se aqui, assim como em outros artistas da contemporaneidade, a promoção do banal, em detrimento do "instante decisivo" ou do espetacular, como objeto fotográfico, colocando em questão a própria autonomia do campo da fotografia entre as diversas outras mídias.

1. Algumas obras dos fotógrafos estrangeiros foram obtidas em cópla DVD intltulada Contacts: a renovação da fotografia contemporánea, França: Arte Video, 2000, e que tem como objetivo acompanhar o percurso do trabalho de criação no curso do processo de elaboração de uma obra fotográfica. A leltura do brasileiro Miguel Rio Branco focalizou sua obra fotográflca Entre os olhos: o deserto. 


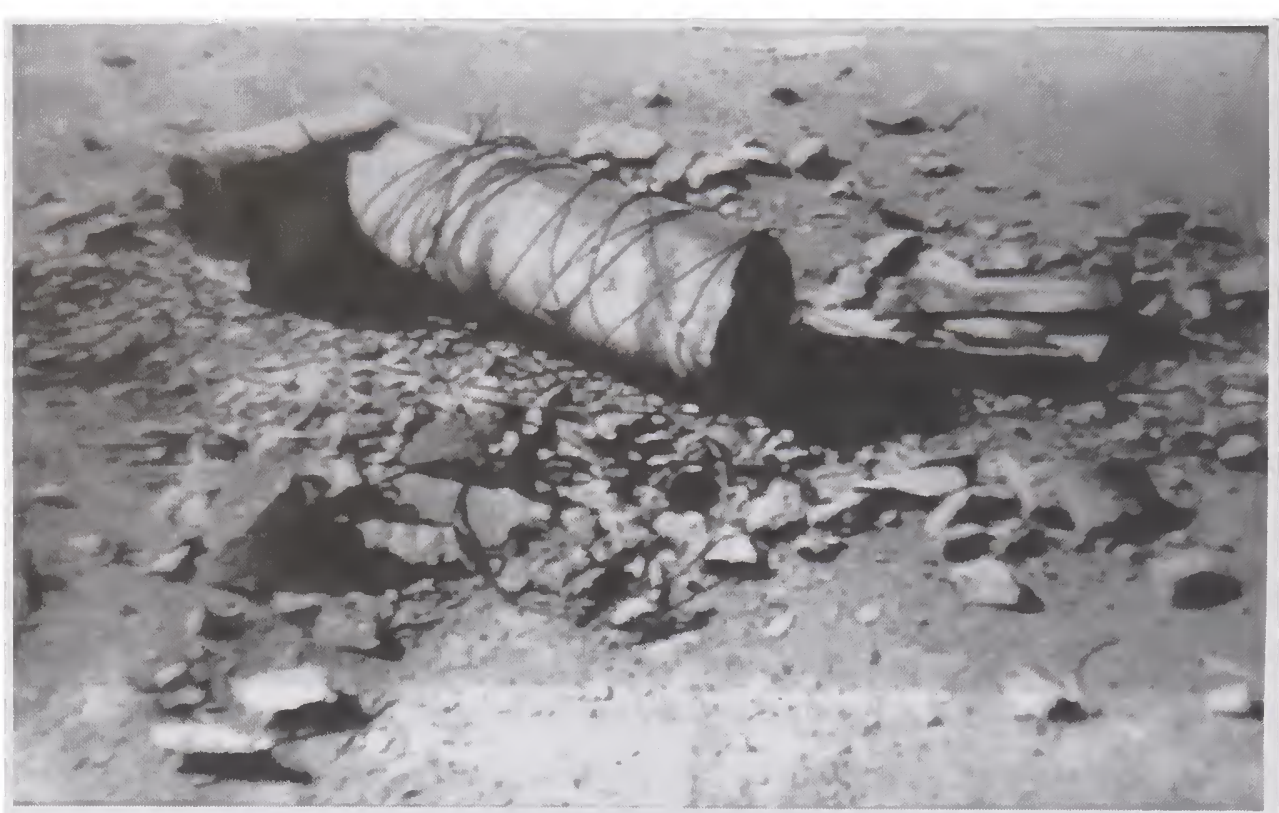

Figura 1 - Lewis Baltz - (DVD Contacts, Paris: La Sept Vidéo, 2000.)

Tais ensaios conduzem-no à idéia de uma experiência insólita, pela instalação de um grande mural que expõe fotos obtidas por câmeras de vigilância. Essas fotos não têm a mesma resolução e perspectiva, o que obriga o espectador a realizar deslocamentos constantes de recuo e aproximação para melhor visualizar cada imagem, resultando, o seu movimento, numa metáfora da própria vigilância e uma ação imperativa das peças sobre o espectador. Com isso, o artista coloca em cheque a idéia de quem vigia e de quem é vigiado, atribuindo à peça uma competência manipuladora sobre o espectador.

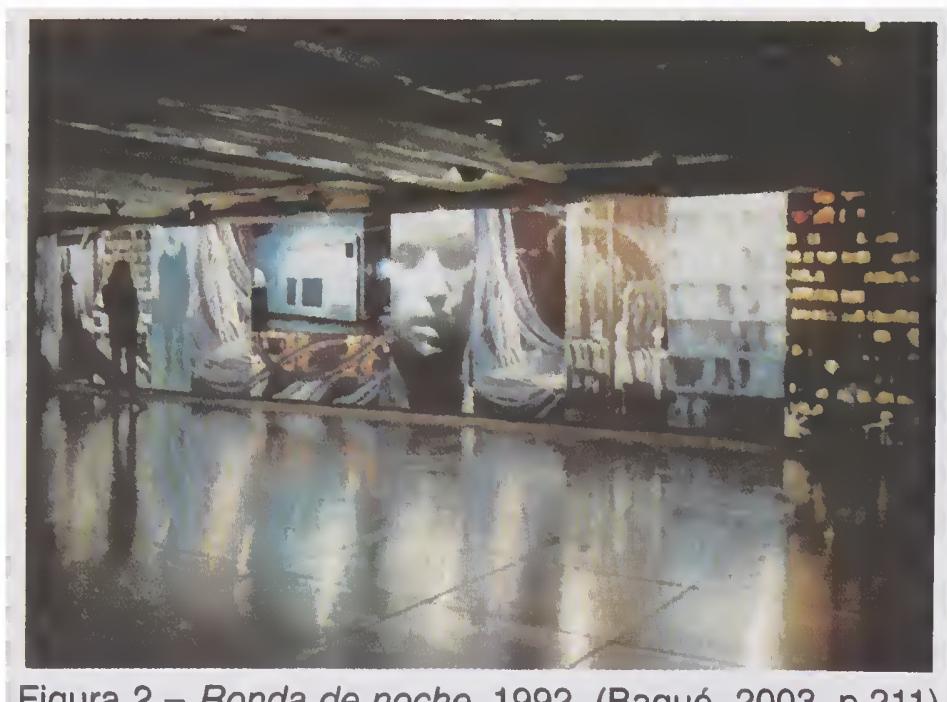

Figura 2 - Ronda de noche, 1992. (Baqué, 2003, p.211) 
Desloca, assim, o postulado de que a fotografia retrata uma realidade pré-existente, conhecida pelo sujeito, que se limita a apreendê-la e fixá-la em sua figuratividade, para conceber o surgimento do sentido no encontro entre o criador e o fruidor. Do mesmo modo, evidencia com seu dispositivo a dificuldade de captar a essência das coisas pela imparcialidade total do sujeito. Ao tentar reproduzir a realidade, o artista se vê impelido a denunciar o caráter ilusório dessa prática (BAQUÉ, 2003, p. 202), pois a escolha do objeto a ser focalizado é já um dos elementos de uma subjetividade, que se constitui e consolida à medida que o ato comunicativo se processa em laços de aproximação e distanciamento dos quais resulta a impressão da maior ou menor objetividade do discurso.

Segundo suas próprias constatações, "a verdade, se verdade existe, está no encontro entre a foto e o espectador"

\section{A realidade arranjada de Thomas Ruff}

O alemão Thomas Ruff, adepto de uma aparente objetividade fotográfica, engrossa a fileira de uma nova geração de artistas europeus, que procuram destituir suas obras de qualquer traço de passionalidade. Sua obra, assim como a de outros artistas alemães do pós-guerra, filiam-se à chamada Nova Objetividade do anos 20, caracterizada pela busca de neutralidade e o "retorno reflexivo sobre a função documental do objeto" (BAQUÉ, p. 131.). Para melhor executar seus propósitos, Ruff começa com sequiências de fotografias de interiores de residências sem a presença humana, pois supunha que ali poderia representar de forma isenta a realidade. Na sua concepção, uma sala com um sofá é uma sala com um sofá, independentemente do estado de espírito daquele que a fotografa. Variações de cor, matiz e luz podem ser dadas, como o fez o artista, mas a cena resultará sempre a mesma, porque ela se impõe em sua objetividade.

Como afirma Dominique Baqué, na obra La fotografía plástica, o objetivo é

Contra tudo isso: afirmar que existe o real, e que dessa realidade o meio fotográfico pode dar, senão o sentido, 
ao menos o testemunho. /.../ O banal em si mesmo, exibido em sua irritante presença: packagings publicitários, rostos lisos, como que esvaziados de toda interioridade, objetos de consumo corrente, camas e alimentos...O real está aí. Tão presente que a diferença entre o real e a sua representação parece diminuir: o real emite, a fotografia transmite." (págs. 131-132)

Em seguida, a experiência se estende a fachadas de casas, que são retocadas pelo computador na tentativa de manter em suas imagens o objeto enxuto, desprovido de anima ou de seus entornos (como árvores, cartazes, janela aberta).

A busca incessante da objetividade leva-o, portanto, ao rearranjo do referente, a uma espécie de desbastamento dos indícios da cultura e da presença humana. O próprio objeto, no entanto, desde que assumido como uma leitura do mundo, que nos faz por exemplo categorizar salas e casas como objetos, é de per si cultural, construído. $\mathrm{O}$ artista entra então num ritmo alucinante de tentativa de despassionalização nos vínculos com o objeto fotográfico que deriva, paradoxalmente, em percurso passionalizado. Construída na base de intervenções tecnológicas sobre o suporte, a foto mostra-se como uma realidade arranjada, resultado do tipo de vínculo entre o sujeito e a empiria. Se o princípio não é novo, ele traz em seu bojo o pressuposto de uma auto-referencialização da foto e a primazia do efeito de sentido sobre o caráter "imitativo" da fotografia.

\section{Encontros pictórico-fotográficos de Jeff Wall}

O canadense Jeff Wall caminha em sentido inverso: restitui o elo de ligação entre fotografia e pintura figurativa, inspirado em pinturas de Brueghel, Manet e Velasquez, abordando, porém, esses vínculos de uma perspectiva crítica.

Esse tipo de foto, chamada de foto-quadro, aparece no princípio dos anos 80, em artistas como Jeff Wall e o francês Jean-Marc Bustamante, tendo como seu expoente crítico Jean-François Chevrier, que designa desse modo uma certa forma fotográfica concebida

Significação $20 \cdot 142$ 
em relação ao modelo pictórico, sem que para isso intervenha o gesto mesmo de pintar. (Baqué, p. 45) Igualmente preocupado com a permanente relação da fotografia com a realidade, o fotógrafo busca inicialmente sua presença na paisagem, mas seus trabalhos mais instigantes consistem na tradução intersemiótica da pintura para a fotografia, por meio da qual intenta fazer compreender o tipo de relação que se estabelece entre os dois discursos, para além das considerações em torno da consolidação do ideal pictórico na fotografia.

$\mathrm{Na}$ passagem da pintura para a fotografia, vários procedimentos ou instâncias podem migrar de um discurso para o outro. É comum evocar o caráter altamente figurativo almejado pela pintura renascentista exponencializado com a descoberta da fotografia. Igualmente fala-se do recurso da instantaneidade, próprio do ato fotográfico, simulado pela pintura. Embora os dispositivos de apreensão/ captação/representação de imagem sejam distintos nos dois suportes, os efeitos basicamente se repetem, com a diferença, já apontada por Barthes, de que a fotografia traz a inscrição de um tempo passado em seu discurso, da idéia do "isso foi", do que deriva a marca documental ou testemunhal da coisa ou do evento representado.

Wall promove justamente essa sensação do efeito obtido pela pintura sobre o espectador, realizando uma foto em que o nível figurativo do quadro é substituído e mantida a mesma diagramação do

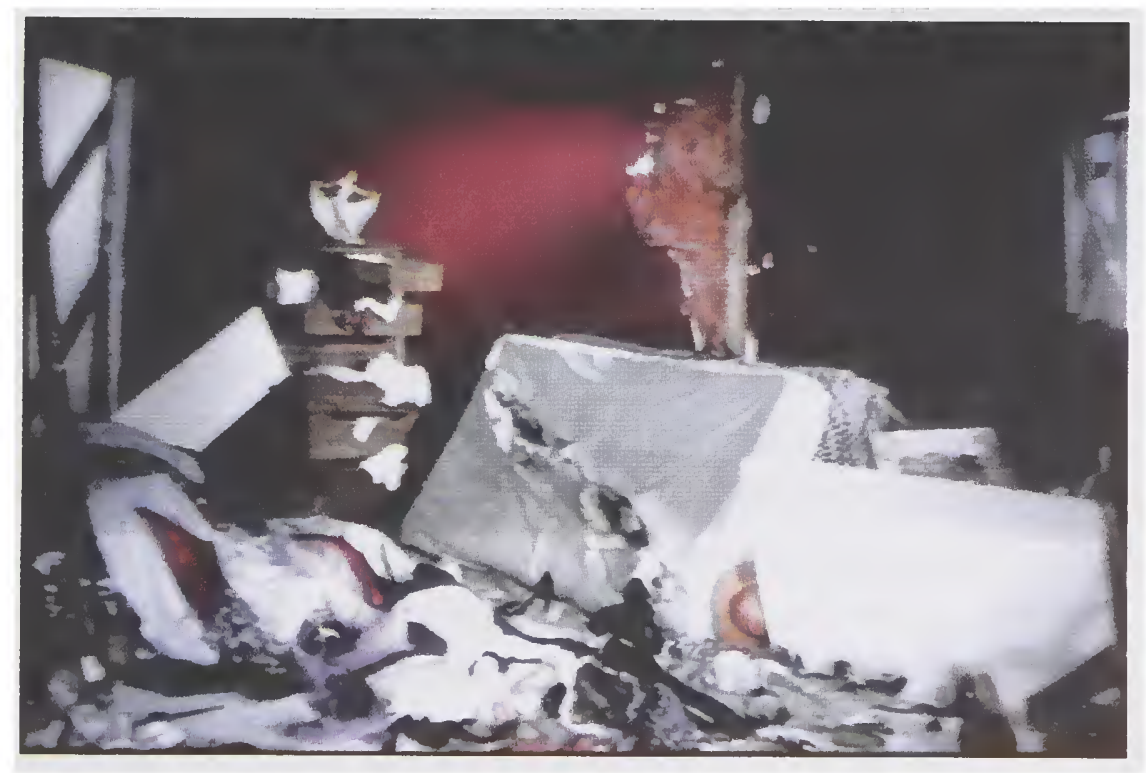

Figura 3 - Jeff Wall - La chambre détruite (DVD Contacts, Paris: La Sept Vidéo, 2000) 
arranjo plástico da imagem. $O$ resultado é surpreendente, porque a tradução da pintura na foto permite uma releitura da primeira, em que se enfatiza o caráter violento expresso na imagem pictórica, e a marcação do ato discursivo em processo no evento retratado. $O$ componente processual manifesta-se na necessidade de reconstrução dos fatos que a fotografia nos impõe.

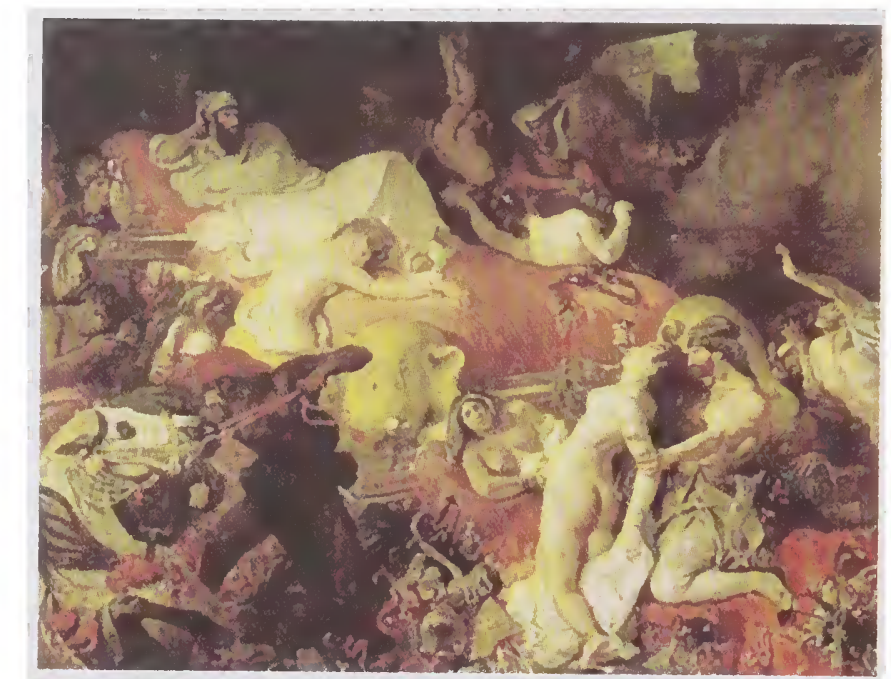

Figura 4 - A morte de Sardanapalo - E. Delacroix

Inspirando-se no quadro do pintor romântico francês Eugéne Delacroix, A morte de Sardanapalo, o fotógrafo projeta uma instalação que servirá de motivo à fotografia do que ele designou $O$ quarto destruído. A semelhança plástica entre os dois discursos pode ser detectada, no plano cromático, pela presença de cores como o branco, com os efeitos de luminosidade sobre a imagem nas mesmas zonas da superfície do quadro, e o vermelho, que está presente na colcha sobre a suntuosa cama, no quadro de Delacroix, e na parede de fundo, na fotografia de Jeff Wall.

A orientação do olhar obedece à mesma seqüência nas duas imagens, garantida pela incidência da luz em movimentos que as recortam topologicamente em forma cruzada. Assim, no quadro, a cabeça do cavalo aterrorizado que se estende em direção a uma das aias mortas ao pé da cama, e o detalhe do corpo de outra mulher sendo esfaqueada na garganta estendendo-se em direção à cabeça de Sardanapalo que aprecia com prazer o massacre de "seus bens" em conjunção com a iminência de sua própria morte. Na foto, repete-se 
a direcionalidade do olhar que se encaminha das roupas brancas, no canto esquerdo inferior, à janela, situada no canto direito superior; $o$ reflexo branco da superfície da mesa virada, passando pelo lençol e finalizando na pequena estatueta branca em cima do gaveteiro no canto esquerdo superior, delineando um diagrama em forma cruzada que atravessa toda a superfície da imagem. Esse diálogo efetivado na composição plástica reitera, no plano temático, o tema da violência, com a diferença de que num caso o destinador narrativo do fazer destruidor está explicitamente manifestado, representado pela figura de Sardanapalo, enquanto que no outro, não aparecem nem os destinadores da ação, nem os sujeitos de estado, tornando-se os próprios objetos os sujeitos estéticos.

Trata-se da imagem de um cômodo destruído, apresentado em cenas sucessivas que vão detalhando partes do todo, como pedaços de paredes, móveis, a presença de objetos de uso pessoal feminino, como botas, chapéus, óculos de sol, braceletes, etc. É inevitável que o espectador efetive a leitura da foto pela recomposição do referente antes de sua destruição e visualize, nesse encontro com as fotos, o processo demolidor, do que resulta o efeito de fazer sentir a violência presente no quadro que lhe serviu de inspiração, ou melhor de "sentir o sentido" como diz Landowski (2001), despertado pelo quadro de Delacroix. A violência de Sardanapalo torna-se então, na fotografia, uma metáfora da violência de nossas sociedades contemporâneas.

O que a foto faz é pôr em relevo a leitura, adaptando-a à empiria da contemporaneidade e desfazendo qualquer possibilidade de apreensão do quadro como uma representação estática, efeito normalmente atribuído à pintura neoclássica. A ausência de seres humanos figurativizados na foto, ao contrário do quadro, revela igualmente um olhar atual sobre a morte. Ela não está nas pessoas, mas naquilo que simboliza suas presenças no mundo, como os objetos que lhes pertencem. A destruição de seus bens simbólicos corresponde ao fim de sua própria identidade na sociedade.

Em outro trabalho, Wall simula uma performance de cenas de guerra, que resultam em fotos tão dramáticas quanto são aquelas que remetem às guerras verdadeiras. Reconstitui, assim, um percurso 
trilhado pelos artistas já mencionados anteriormente, e nos faz compreender que a cena do quadro (e de outros que o artista reconstrói) são meros pretextos para a criação do objeto fotográfico. O referente não é mais anterior ao ato fotográfico. Ele se constrói no ato, se refaz a cada leitura e impulsiona um novo olhar sobre o já visto e já sabido. Tal como nos quadros sobre a Condição Humana de Magritte, a realidade resulta numa fabricação, que acaba se convertendo em realidade, senão do ponto de vista inteligível, pelo menos, e sobretudo, de um ponto de vista sensível. Nesse sentido, o recurso à instalação ou à performance como motivo fotográfico dota o ato discursivo de um valor enunciativo que é o de realizar-se, enquanto instalação ou performance, ao mesmo tempo em que o ato fotográfico se desenvolve. A idéia da instalação remete também ao cruzamento da fotografia e da escultura, pondo em relevo o caráter híbrido da arte pós-moderna. Como corolário, neutralizam-se as distinções tradicionais entre os gêneros discursivos, que se realizam em co-presença como manifestações de um mesmo processo semiótico em ato.

De acordo com Dominique Baqué (op. cit., p. 201), as imagens que cruzam foto, cinema, vídeo, instalação, etc., propõem uma interrogação crítica sobre as condições da percepção, sobre o significado da imagem e sua recepção. Nesse sentido, as obras que resultam dessa mestiçagem inventam novas configurações plásticas e pensam o 'visual' contemporâneo.

\section{O mundo alucinante de Sophie Calle}

A fotógrafa Sophie Calle, ao voltar a Paris, vê-se como estrangeira em sua cidade. $\mathrm{O}$ tempo a havia afastado do cotidiano parisiense, que agora ela desejava penetrar. Sophie então busca no olhar do outro a porta de entrada para a cidade e sai a perseguir as pessoas pelas ruas, fotografando-as em suas rotineiras atividades urbanas. Assim, elas roteirizam seu reencontro com a cidade até Sophie eleger, em determinado momento, um único indivíduo a ser seguido. A redescoberta da cidade, motivo que a fotógrafa alega ter para realizar tal ensaio, é abandonado quando ela parte para Veneza no intuito de seguir sua nova presa fotográfica. Fotografa Veneza 
repetindo as mesmas tomadas realizadas pelo sujeito que ela persegue. A cidade é motivo acidental para a sua busca, pano de fundo para um objetivo mais íntimo do artista: a compreensão de sua realidade pessoal.

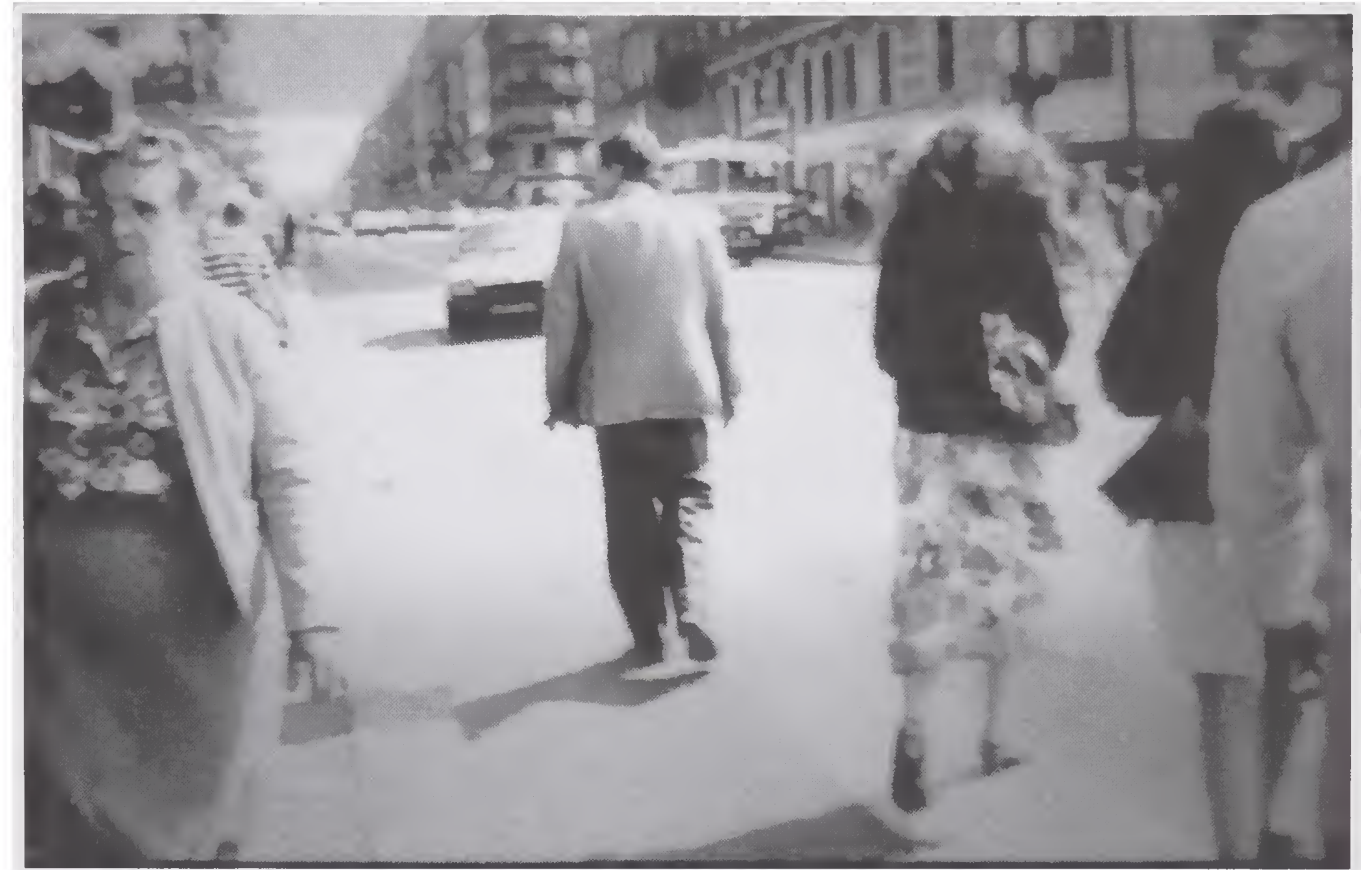

Figura 5 - Sophie Calle (DVD Contacts, Paris: La sept vidéo, 2000.)

Obsessivamente Sophie mergulha sobre o olhar do outro, tentanto ver-se pelo visor alheio. Caminha pela cidade guiada por esse olhar que lhe comanda posições e desejos estrangeiros. Nem Paris, nem Veneza são os objetos de sua lida. Seu ensaio busca a realidade do outro, a visão do outro como vetor de sua própria realidade.

Sophie finaliza seu ensaio voltando à Paris e contratando, por intermédio de sua mãe, um detetive para persegui-la e fotografá-la em seu dia-a-dia. Para quem até então tinha pautado todos os seus movimentos por olhares externos, Sophie concebe um desfecho de raro rigor lógico: compartilha seu cotidiano com o olhar alheio.

Nesse caso, não se trata necessariamente de uma busca do efeito de realidade, mas da elaboração de um referente novo para as fotos transformando-as numa experiência multissensorial que extrapola o nível de interpretação baseada no reconhecimento 
das figuras e na atribuição de sentidos fixos aos discursos. Não se trata mais da fotografia como arte, mas da fotografia procedimento, recurso de compreensão do próprio movimento de estar no mundo.

\section{A fotografia "entre os olhos" de Miguel Rio Branco}

Em "Entre os olhos, o deserto" Miguel Rio Branco cria, através da diagramação, uma combinação progressiva de sentidos. Imagens combinadas em dípticos e trípticos formam uma progressão geométrica de significados que se sustenta pela coerência sintática proposta pelo autor.

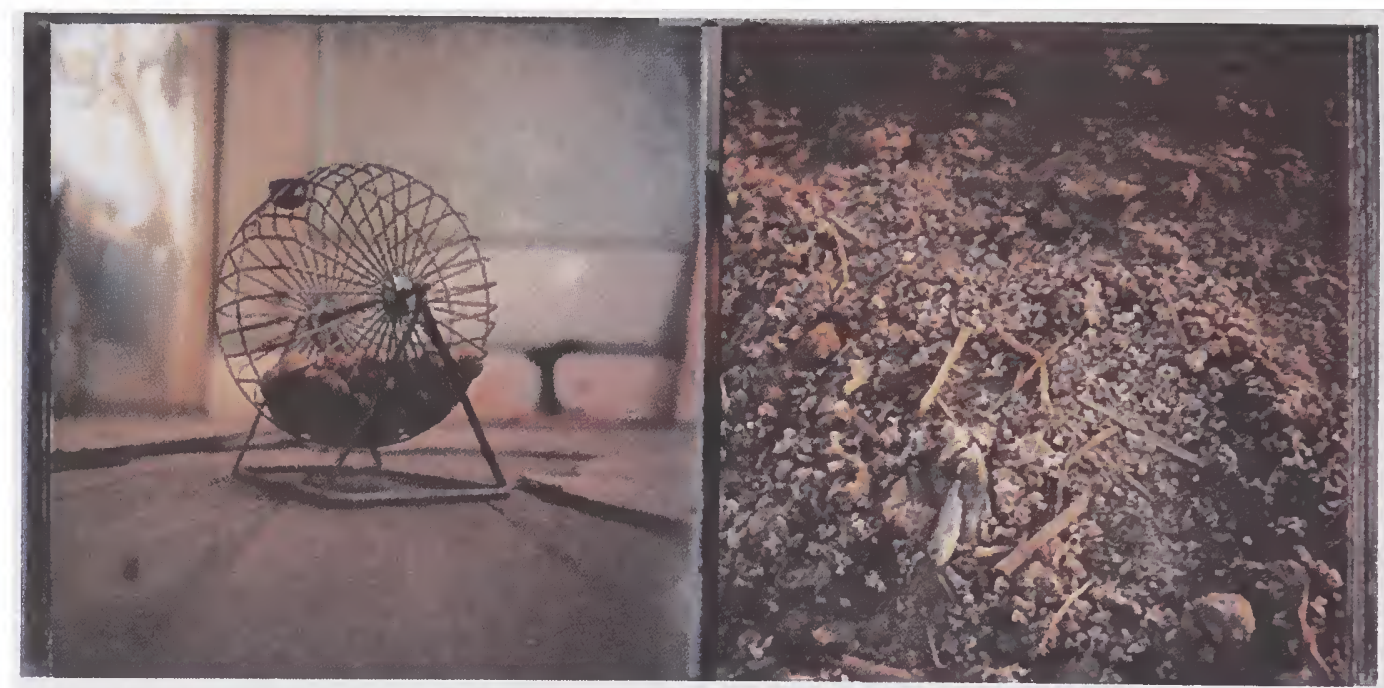

Figura 6 - Entre os olhos: o deserto - Miguel Rio Branco

O universo de Miguel é povoado por olhos, ossos, luvas, tubarões voadores, mãos e flores. $O$ deserto é a presença mais constante. Pontua todo o ensaio como metáfora do vazio absoluto, onde nosso olhar pode voar livre da referencialidade. O título do livro nos adianta tal potencialidade metafórica do deserto. Através da metáfora despimos o olhar da atitude referencial e da teimosia de construir, por menor que seja o fragmento, um mundo figurativo e aprisionável.

Em seu livro Rio Branco destrói o referente através da aproximação excessiva, do desfoque, da retícula estourada e, principalmente, da relação entre os dessemelhantes conteúdos das imagens e de suas semelhanças plástico-expressivas. $\mathrm{O}$ autor explora a quebra da harmonia estética pela dessemelhança de seus conteúdos figurativos. 
Miguel propõe uma relação menos referencial e mais voltada ao nível da expressão plástica. Interessa a ele a similitude entre as formas da expressão e não entre os conteúdos. Desta maneira mãos compartilham um tríptico com espinhos e com um globo de metal usado para sorteios. A divergência semântica entre os objetos desarmam o olhar e assim revelam a semelhança plástica entre as superfícies construídas.

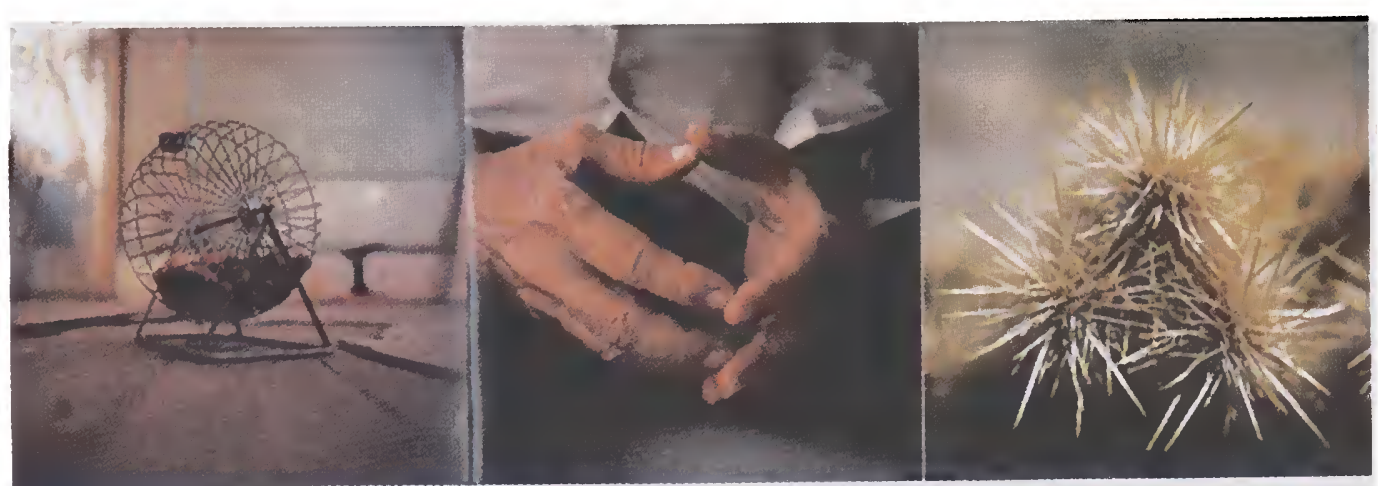

Figura 7 - Entre os olhos: o deserto - Miguel Rio Branco

Acompanha o livro um dvd, onde as imagens são apresentadas apenas como trípticos e acompanhadas pela narração de um texto de David Levi Strauss. No dvd, as fotografias ganham outra dimensão devido a troca de suporte e a nova relacão entre o texto e as imagens. David, em seu texto, descreve de forma poética o mito da caverna de Platão e a mitológica história de Orfeu. Ambas narrativas onde a luz é protagonista. Inevitável não traçar uma analogia entre a posição que ocupamos, ao ver a obra, e as duas histórias. Ao ver o dvd, as imagens surgem à nossa frente como as sombras ao fundo da caverna de Platão. Elas são os vestígios do mundo real, traços da realidade que nos satisfazem através da referencialidade. Vemos as imagens tentando satisfazer esse vício referencial. $\mathrm{Na}$ verdade, as vemos na tentativa de construir o que ali não mais se encontra, o "isso foi" da fotografia. Mas o autor habilmente nos nega o referente e força assim um olhar aquém do conteúdo, um olhar voltado a enxergar a topografia plástica das fotos e suas relações estéticas.

Assim, como Orfeu, somos traídos ao olharmos para trás em busca da certeza referencial. 


\section{Considerações finais}

O traço comum entre todas as peças comentadas é o fato de que nelas o nível figurativo pouco conta, ou melhor, está a serviço seja da dimensão plástica da imagem e de seus efeitos, seja de um procedimento, operacionalizado pelo ato fotográfico.

As atribuições de fixação do instante decisivo, de flagrante, ou de testemunho dadas à foto são igualmente preteridas, mesmo no paradigma objetivista de T. Ruff, em favor de um "novo" objeto fotográfico, surgido do encontro entre o homem e os objetos do mundo ou entre o homem e os outros seres humanos. Dessa relação, nem sempre inusitada, resulta a reflexão sobre as potencialidades da fotografia e, paradoxalmente, de suas limitações enquanto campo autônomo de apreensão perceptiva.

Nas fotos (baseadas em instalação) de J. Wall, as figuras contribuem para acentuar as dimensões topológica, cromática e eidética, dirigindo o olhar para uma topografia da imagem que se assemelha à linguagem pictórica. No entanto, a fotografia não se anula, destaca, ao contrário, a força do discurso na produção de sentidos para além do que seus traços figurativos propõem. Por isso, referentes dessemelhantes estão aptos a produzir os mesmos efeitos sobre o fotógrafo e o espectador.

Sem recorrer à igual estratégia, mas pondo em evidência a dimensão plástica das imagens, é o que faz Miguel Rio Branco. Nele, o dispositivo instaura efeitos de sentido de ordem perceptivosensorial, enquanto em Wall, a metáfora da violência não só faz sentido, mas é sentida, mesmo sem ser explicada.

L. Baltz dá um novo estatuto a coisas até então desprezadas pelas axiologias coletivas, que se convertem pela mediação da foto em objeto de percepção e reflexão do humano. Não é, porém, a sua figuratividade que interessa, mas a possibilidade de ser apreendida na materialidade física do objeto, despida dos revestimentos culturais que cristalizaram os objetos estéticos. Mais ou menos como uma possibilidade de apreensão do objeto em estado puro, anterior à sua significação pelo olhar humano.

$\overline{\text { Significação } 20 \cdot 150}$ 
Na mesma direção de Baltz, embora com procedimentos distintos, encaminha-se a arte de Ruff. Ao arranjar a realidade que fotografa, desbastando-a de seus "acessórios culturais", o artista delineia a composição do referente, em seus traços mais elementares, ao mesmo tempo em que revela a sua conversão em objeto fotográfico. Ato contraditório, que denuncia um certo puritanismo do objeto, como diria Baqué, e uma impotência do artista que se diz "eu" a cada nova inscrição do outro (objetos, rostos ou atos) em superfície construída.

Em todos esses casos, fica clara a estratégia de autoreferencialização do objeto fotográfico, ainda que por procedimentos e dispositivos distintos.

Resta perguntar como inserir a empreitada obsessiva de Sophie Calle em tal trajetória. Mais do que construir o objeto a ser fotografado, Sophie se deixa conduzir pelo olhar do outro para eleger tanto o que fotografar, quanto para se ver, tal qual um narciso caminhante, olhando o próprio mundo em que se insere e que ela mesma constrói.

O que é percebido não tem o menor interesse, mas sim a realização do ato de um encontro, entre um outro eu mesmo (como diria Balzac na obra Os camponeses), que se institui como o foco de atenção da autora e do espectador. Nessa busca interminável, em que a imagem ideal nunca aparece, configura-se a metáfora do fazer fotográfico, em especial do percurso efetivado por todos os artistas aqui apresentados. Insinua-se na leitura de todas essas obras a sensação de que não há nada a fotografar, nenhum detalhe, tomada, ângulo a eleger. $O$ fazer fotográfico é que é constitutivo do real e se afirma como a formalização de um encontro em que se engendram, hic et nunc, o sujeito perceptivo e o objeto da percepção. 


\section{Bibliografia}

BAQUÉ, D. La fotografía plástica. Barcelona: Editorial Gustavo Gili, 2003.

BARTHES, R. O óbvio e o obtuso: ensaios críticos III. Rio de Janeiro: Nova Fronteira, 1990.

A câmara clara: nota sobre a fotografia. Rio de Janeiro: Nova Fronteira, 1984.

BECKETT, W. História da pintura. Rio de Janeiro: Ática, 1997.

BRANCO, M. R. Entre os olhos, o deserto. São Paulo: Cosac \& Naify, 2001.

FONTANILLE, J. Point de vue: perception et signification. Sémiotique et littérature: essais de méthode. Paris: PUF, 1999, p. 41- 62 .

GREIMAS, A.-J. Semiótica figurativa e semiótica plástica. In: Significação, Araraquara,SP: Centro de Estudos Semióticos, 4, 1984, p. 18-46,.

LANDOWSKI, E. O olhar comprometido. Galáxia: Revista transdisciplinar de comunicação, semiótica, cultura. São Paulo: EDUC, $\mathrm{n}^{0} 2,2001$.

MACHADO, A. Anamorfoses cronotópicas ou a quarta dimensão da imagem. In: PARENTE, A. (org.), Imagem máquina: a era das tecnologias do virtual, Rio de Janeiro: Ed. 34, 1993, p. 100116.

PEIXOTO, N. B. Passagens da imagem: pintura, fotografia, cinema, arquitetura. In: PARENTE, A. (org.), Imagem máquina: a era das tecnologias do virtual. Rio de Janeiro: Ed. 34, 1993, p. $237-$ 252.

THÜLERMANN, F Paul Klee. Analyse sémiotique de trois peintures. Lausanne: L'age d'homme, 1982. 